\title{
THE USE OF VIBRATION CHARACTERISTIC TO UPDATE THE STRUCTURE MODEL
}

\author{
PHAM XUAN KHANG \\ Research Institute for Transportation Science and Technology
}

\begin{abstract}
Many authors studied algorithms adjusting the structure model based on modal data. This paper proposes an algorithm to detect the structure model using correlation factors between experimental and theoretical modal data in a damage library. The result from an experiment on 1-40 bridge (New Mexico USA) is presented to illustrate.
\end{abstract}

\section{Introduction}

Recently, the research of structure diagnosis using modal data has been developing rapidly. Many damage detection algorithms have been proposed to identify whether or not damage has occurred and to locate damage. However, in order to evaluate the load carrying capacity of a structure, its mathematical model need to be built correctly, relying on experimental data. The model will be complete if its modal data approximates the experimental modal data. The major problem in most identification algorithms is the incompleteness of the measured data: only a few points in structure are measured over a limited frequency range, but the finite element (FE) model of the structure contains a large number of degree of freedom. Therefore, updating a structure model relying on vibration data is difficult.

Detecting a model according to statistical technique is one of the algorithms used by many researchers, This technique was first suggested by Cawley and Adams [5]. By this technique, many possible damage scenarios within the finite element model are considered, and their effects on the predicted natural vibrations computed. The damage model is then identified as the one that seems to be closest to measured data. The two major problems with this technique are: 1) the time required to calculate a new set of natural vibration for every damage scenario and, 2) the algorithms to determine the actual damage correspond with one of the modeled scenarios. This paper develops an algorithm to detect the possible real models in the damage library. 


\section{Model updating overview}

Although the range of model updating algorithms is large, the basic concepts are similar. A given structure can be modeled analytically and predictions of the response of the system can be made. Its response may also be measured and compared to the theoretical predictions. If results of the theoretical analysis and the measurements are different then some parameters of the theoretical model should be changed to reflect the characteristics of the physical structure. Assuming that the underlying structure of the model is satisfactory then parameters can be accepted. This is known as model updating.

$\mathrm{FE}$ analysis and experimental modal analysis (EMA) are two basic constituents of model updating algorithms for mechanical structures. FE analysis is a standard technique for modeling the dynamics of mechanical structures. In this technique the structure is split into regions of simple geometry (called elements) which intersect at points (called nodes). The equation systems of motion can be written as follows

$$
\mathbf{M} \ddot{\mathbf{q}}+\mathbf{K} \mathbf{q}=\mathbf{f},
$$

where

$\mathbf{M}, \mathbf{K}$ are the mass and stiffness matrices,

$\mathbf{q}$ is the vector of generalized coordinates, that is the displacement at the nodes of structure,

$\mathbf{f}$ is the force applied to the structure at the nodes, and the dot denotes differentiation with respect to time.

The natural frequencies and mode shapes are obtained by solving the following eigenproblem:

$$
\left[-\omega_{i}^{2} \cdot \mathbf{M}+\mathbf{K}\right] \boldsymbol{\phi}_{i}=0
$$

here $\omega_{i}$ is $i^{i t h}$ natural frequency and $\phi_{i}$ is the corresponding mode shape.

Damping has not been mentioned in equation system (2.1). In general, damping is difficult to incorporate into a finite element analysis and furthermore its value is unknown.

In dynamic testing, the structure is usually excited by harmonic force or impulse force and its responses are measured. Using the Fast Fourier Transform for input and output signals, the transfer functions can be determined, then experimental modal data (natural frequencies, damping ratios, mode shapes) can be calculated by analyzing the transfer function $[2,4]$. In this paper we assume modal data is given and do not discuss the measured data analysis to get the experimental vibration characteristics of the structure. 


\section{Model updating technique}

Let's assume that the library of the theoretical modal data correspondings to the damage scenarios are given. For each damage type, we have to use the appropriate element model for calculating. For example, the physical or geometrical properties can be changed to simulate the damage. Because the changes of frequency are less sensitive to damage $[2,5]$, especially the minor damage, in this case the changes in mode shapes will be used to update the structure model. When the structure is damaged, mode shapes before and after damage are different. Therefore the appropriated model in the damage library may be detected using correlative comparison of measured and theoretical mode shapes.

Denote $x_{i}(j)(i=1, m)$ is $i^{\text {th }}$ mode shape measured at point $j(j=1, n)$, here $n$ is the number of measured points, $m$-number of measured natural modes. Denote $y_{k \ell}(j)(\ell=1, m)$ is $\ell^{t h}$ mode shape measured at point $j$ corresponding $k^{t h}$ damage scenario.

The correlation factor between $x_{i}$ and $y_{k \ell}$ can be written as follows:

$$
R\left(x_{i}, y_{k \ell}\right)=\frac{\left(\sum_{j=1}^{n} x_{i}(j) \cdot y_{k \ell}(j)\right)^{2}}{\sum_{j=1}^{n} x_{i}^{2}(j) \cdot \sum_{j=1}^{n} y_{k \ell}^{2}(j)}
$$

with $i=1, \ldots, m ; \ell=1, \ldots, m ; k=1, \ldots, p(p$ is the number of theoretical damage scenarios).

If the $k^{t h}$ theoretical damage model is an appropriate model of the structure then:

$$
R\left(x_{i}, y_{k \ell}\right)= \begin{cases}1 & i=\ell, \\ 0 & i \neq \ell,\end{cases}
$$

But it is difficult to get the correct data, which the correlation factor should take in order to guarantee good results. So that $k^{\text {th }}$ theoretical damage scenario seems to be the appropriate model when:

$$
R\left(x_{i}, y_{k \ell}\right)= \begin{cases}>0.9 & i=\ell \\ <0.1 & i \neq \ell .\end{cases}
$$

Denote $R_{k}=\{r\}_{i, \ell=1, n}=\left\{R\left(x_{i}, y_{k \ell}\right)\right\}_{i, \ell=1, n}$ is the correlation matrix between $x_{i}$ and $y_{k \ell}$ for $k^{t h}$ theoretical damage case, so $k^{t h}$ theoretical damage scenario is the appropriate model if

$$
\begin{aligned}
& \{r\}_{i, j}>0.9 \quad i=\ell \\
& \{r\}_{i, j}<0.1 \quad i \neq \ell .
\end{aligned}
$$


According to the restriction of the detection criteria, the value 0.9 and 0.1 can be changed. Using expression (3.1) mode shapes are not required to normalize because it is normalized automatically. When all the damage scenarios do not satisfy (3.3), it means that the damage library does not have a theoretical model corresponding with the experimental structure. The new model need to be determined and add to damage library to make the library more complete.

\section{The simulated example}

The experimental and theoretical data used on this study come from tests performed on the I-40 Bridge over the Rio Grande in New Mexico. Figure 1 shown an elevation view of the portion of the bridge and its cross-section geometry.
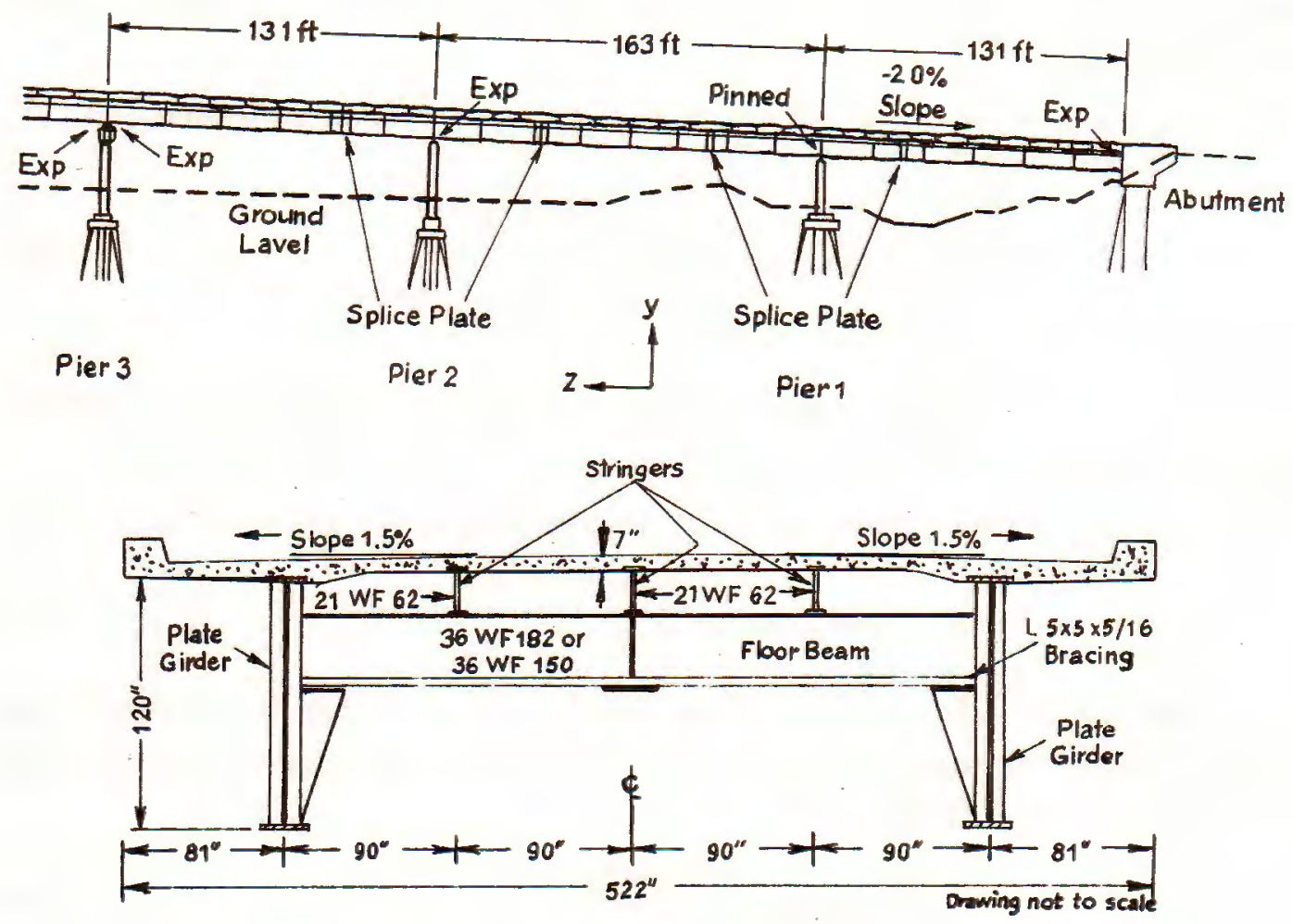

Fig. 1. The I-40 bridge

In the case study, a damage library is given from measured data, then theoretical data is used to detect the mathematicsl model of the bridge.

\subsection{Damage Description}

In the damage library, there are 5 cases of measured modal data: 
+ Un damage.

+ Damage: Damage was introduced by making various torch cuts in the web and flange of the north girder. It contains:

- E-1: 2 foot long, $3 / 8$ inch wide cut through web centered at midheight of the web.

- E-2: First cut was continued to the bottom of the web.

- E-3: The flange was then cut halfway in from either side directly below the cut in the web.

- E-4: The flange was cut through leaving the top $4^{f t}$ of the web and the top flange.

These damages and measured mode shapes are given in table 1.

Table 1. Cases for Measured Damage

Natural Frequency in damage cases $(\mathrm{Hz})$

$\begin{array}{rrrrrrr} & \text { Theory } & \text { Case 1 } & \text { Case 2 } & \text { Case 3 } & \text { Case 4 } & \text { Case 5 } \\ \text { Mode 1 } & 2.05 & 2.48 & 2.52 & 2.52 & 2.46 & 2.30 \\ \text { Mode 2 } & 2.72 & 2.96 & 3.00 & 2.99 & 2.95 & 2.84 \\ \text { Mode 3 } & 3.28 & 3.50 & 3.57 & 3.52 & 3.48 & 3.49\end{array}$

The first mode shape

$\begin{array}{lrrrrrr} & \text { Theory } & \text { Case 1 } & \text { Case 2 } & \text { Case 3 } & \text { Case 4 } & \text { Case 5 } \\ \text { N1 } & 0.000548 & 2.57 \mathrm{E}-04 & 3.95 \mathrm{E}-03 & 5.56 \mathrm{E}-03 & 4.48 \mathrm{E}-03 & 8.40 \mathrm{E}-03 \\ \text { N2 } & 0.039121 & 6.90 \mathrm{E}-03 & 0.218 & 0.226 & 0.2 & 0.101 \\ \text { N3 } & 0.053435 & 0.01 & 0.32 & 0.316 & 0.295 & 0.143 \\ \text { N4 } & 0.038016 & 8.01 \mathrm{E}-03 & 0.257 & 0.246 & 0.231 & 0.11 \\ \text { N5 } & -0.000008 & -1.66 \mathrm{E}-05 & -6.08 \mathrm{E}-03 & 0.037 & 3.07 \mathrm{E}-03 & 0.013 \\ \text { N6 } & -0.053636 & -0.014 & -0.454 & -0.425 & -0.389 & -0.204 \\ \text { N7 } & -0.07595 & -0.023 & -0.732 & -0.684 & -0.636 & -0.368 \\ \text { N8 } & -0.051216 & -0.015 & -0.491 & -0.475 & -0.427 & -0.251 \\ \text { N9 } & -0.000081 & -4.56 \mathrm{E}-04 & -0.015 & -0.016 & 0.12 & -7.19 \mathrm{E}-03 \\ \text { N10 } & 0.029742 & 8.62 \mathrm{E}-03 & 0.268 & 0.225 & 0.25 & 0.131 \\ \text { N11 } & 0.039107 & 0.01 & 0.314 & 0.306 & 0.293 & 0.177 \\ \text { N12 } & 0.026713 & 7.54 \mathrm{E}-03 & 0.23 & 0.225 & 0.218 & 0.118 \\ \text { N13 } & 0.000377 & 4.23 \mathrm{E}-04 & 0.015 & 9.16 \mathrm{E}-03 & 0.014 & 0.013 \\ \text { S1 } & 0.000546 & 3.02 \mathrm{E}-04 & 0.01 & 0.013 & 9.50 \mathrm{E}-03 & 0.012 \\ \text { S2 } & 0.039066 & 7.46 \mathrm{E}-03 & 0.263 & 0.223 & 0.208 & 0.204 \\ \text { S3 } & 0.053358 & 0.01 & 0.372 & 0.331 & 0.297 & 0.292 \\ \text { S4 } & 0.037979 & 8.12 \mathrm{E}-03 & 0.279 & 0.26 & 0.226 & 0.232\end{array}$




\begin{tabular}{|c|c|c|c|c|c|c|}
\hline & Theory & Case 1 & Case 2 & Case 3 & Case 4 & Case 5 \\
\hline S5 & -0.00001 & 2.01E-04 & $4.90 \mathrm{E}-03$ & 7.27E-03 & $2.68 \mathrm{E}-03$ & 0.014 \\
\hline 56 & -0.053752 & -0.014 & -0.494 & -0.441 & -0.405 & -0.5 \\
\hline S7 & -0.076165 & -0.021 & -0.741 & -0.68 & -0.625 & -0.964 \\
\hline S8 & -0.051378 & -0.014 & -0.486 & -0.454 & -0.418 & -0.535 \\
\hline S9 & -0.000081 & $-3.67 \mathrm{E}-04$ & -0.019 & -0.014 & -0.013 & -0.023 \\
\hline $\mathrm{S} 10$ & 0.029472 & $7.52 \mathrm{E}-03$ & 0.278 & 0.25 & 0.226 & 0.252 \\
\hline 11 & 0.039088 & 0.01 & 0.353 & 0.329 & 0.313 & 0.342 \\
\hline S12 & 0.026691 & $6.99 \mathrm{E}-03$ & 0.247 & 0.221 & 0.217 & 0.226 \\
\hline S13 & 0.000376 & $4.34 \mathrm{E}-04$ & 0.013 & 0.014 & 0.011 & 0.011 \\
\hline \multicolumn{7}{|c|}{ The second mode shape } \\
\hline & Theory & Case 1 & Case 2 & Case 3 & Case 4 & Case 5 \\
\hline N1 & 0.000257 & $1.73 \mathrm{E}-04$ & $3.70 \mathrm{E}-03$ & $3.15 \mathrm{E}-03$ & $2.90 \mathrm{E}-03$ & $6.64 \mathrm{E}-03$ \\
\hline N2 & 0.009626 & $5.55 \mathrm{E}-03$ & 0.171 & 0.194 & 0.182 & 0.247 \\
\hline N3 & 0.021012 & 8.38E-03 & 0.258 & 0.285 & 0.277 & 0.365 \\
\hline N4 & 0.020227 & $6.98 \mathrm{E}-03$ & 0.218 & 0.236 & 0.23 & 0.292 \\
\hline N5 & -0.000223 & $-1.37 \mathrm{E}-04$ & $-3.76 \mathrm{E}-03$ & 8.37E-03 & $4.29 \mathrm{E}-04$ & $2.19 \mathrm{E}-03$ \\
\hline N6 & -0.052309 & -0.014 & -0.433 & -0.435 & -0.441 & -0.495 \\
\hline N7 & -0.080272 & -0.024 & -0.715 & -0.711 & -0.73 & -0.797 \\
\hline N8 & -0.056831 & -0.016 & -0.49 & -0.495 & -0.498 & -0.55 \\
\hline N9 & -0.000063 & $-5.35 \mathrm{E}-04$ & -0.016 & -0.016 & -0.016 & -0.015 \\
\hline N10 & 0.035573 & 8.87E-03 & 0.273 & 0.263 & 0.277 & 0.322 \\
\hline N11 & 0.047852 & 0.011 & 0.322 & 0.307 & 0.322 & 0.384 \\
\hline N12 & 0.033257 & $8.43 \mathrm{E}-03$ & 0.246 & 0.234 & 0.252 & 0.297 \\
\hline N13 & 0.000587 & $4.72 \mathrm{E}-04$ & 0.014 & 0.015 & 0.017 & 0.017 \\
\hline S1 & -0.000254 & $-2.93 \mathrm{E}-04$ & $-6.18 \mathrm{E}-03$ & $-7.03 \mathrm{E}-03$ & $-8.38 \mathrm{E}-03$ & $-4.87 \mathrm{E}-04$ \\
\hline $\mathrm{S} 2$ & -0.00952 & $-7.62 \mathrm{E}-03$ & -0.222 & -0.211 & -0.234 & -0.104 \\
\hline S3 & -0.020799 & -0.011 & -0.322 & -0.313 & -0.34 & -0.154 \\
\hline S4 & -0.020065 & $-8.42 \mathrm{E}-03$ & -0.242 & -0.229 & -0.252 & -0.122 \\
\hline S5 & 0.000225 & $1.11 \mathrm{E}-04$ & $1.73 \mathrm{E}-03$ & 4.84E-03 & $1.24 \mathrm{E}-03$ & $7.41 \mathrm{E}-04$ \\
\hline S6 & 0.052253 & 0.016 & 0.468 & 0.464 & 0.48 & 0.298 \\
\hline S7 & 0.080227 & 0.024 & 0.714 & 0.711 & 0.737 & 0.559 \\
\hline S8 & 0.056803 & 0.017 & 0.49 & 0.479 & 0.504 & 0.323 \\
\hline S9 & 0.000062 & 4.27E-04 & 0.03 & 0.022 & 0.021 & 0.016 \\
\hline S10 & -0.03545 & $-9.97 \mathrm{E}-03$ & -0.292 & -0.279 & -0.26 & -0.116 \\
\hline S11 & -0.047686 & -0.014 & -0.39 & -0.377 & -0.378 & -0.169 \\
\hline S12 & -0.033145 & $-9.54 \mathrm{E}-03$ & -0.268 & -0.258 & -0.261 & -0.108 \\
\hline S13 & -0.000586 & $-5.61 \mathrm{E}-04$ & -0.014 & -0.016 & -0.021 & $-6.02 \mathrm{E}-03$ \\
\hline
\end{tabular}


The third mode shape

Theory Case 1 Case 2 Case 3 Case 4 Case 5

$\begin{array}{rrrrrrr}\text { N1 } & 0.000839 & 4.72 \mathrm{E}-04 & 8.17 \mathrm{E}-03 & 6.18 \mathrm{E}-03 & 8.38 \mathrm{E}-03 & 0.016 \\ \text { N2 } & 0.053185 & 0.014 & 0.443 & 0.393 & 0.433 & 0.405 \\ \text { N3 } & 0.062276 & 0.019 & 0.597 & 0.53 & 0.583 & 0.543 \\ \text { N4 } & 0.034238 & 0.013 & 0.404 & 0.355 & 0.392 & 0.364 \\ \text { N5 } & 0.000534 & 7.16 \mathrm{E}-04 & 0.024 & 0.017 & 0.021 & 0.021 \\ \text { N6 } & 0.010745 & 4.48 \mathrm{E}-03 & 0.151 & 0.134 & 0.152 & 0.135 \\ \text { N7 } & 0.034365 & 1.04 \mathrm{E}-03 & 0.049 & 0.043 & 0.051 & 0.036 \\ \text { N8 } & 0.033865 & 3.87 \mathrm{E}-03 & 0.119 & 0.105 & 0.105 & 0.102 \\ \text { N9 } & -0.000128 & -5.11 \mathrm{E}-04 & -0.016 & -0.015 & -0.016 & 0.015 \\ \text { N10 } & -0.040139 & -0.014 & -0.435 & -0.392 & -0.423 & -0.399 \\ \text { N11 } & -0.059494 & -0.02 & -0.603 & -0.558 & -0.597 & -0.56 \\ \text { N12 } & -0.043291 & -0.016 & -0.497 & -0.464 & -0.501 & -0.469 \\ \text { N13 } & -0.000762 & -8.95 \mathrm{E}-04 & -0.019 & -0.025 & -0.032 & -0.029 \\ \text { S1 } & 0.000845 & 4.78 \mathrm{E}-04 & 0.015 & 1.30 \mathrm{E}-02 & 0.019 & 0.021 \\ \text { S2 } & 0.053301 & 0.014 & 0.448 & 0.384 & 0.428 & 0.418 \\ \text { S3 } & 0.0625 & 0.018 & 0.581 & 0.502 & 0.559 & 0.543 \\ \text { S4 } & 0.034395 & 0.011 & 0.368 & 0.311 & 0.349 & 0.341 \\ \text { S5 } & 0.000537 & 6.52 \mathrm{E}-04 & 0.024 & 0.019 & 0.19 & 0.022 \\ \text { S6 } & 0.010765 & 4.28 \mathrm{E}-03 & 0.125 & 0.123 & 0.129 & 0.13 \\ \text { S7 } & 0.034527 & 4.64 \mathrm{E}-04 & 0.011 & 0.015 & 7.65 \mathrm{E}-03 & 0.013 \\ \text { S8 } & 0.034052 & 3.39 \mathrm{E}-03 & 0.123 & 0.088 & 0.114 & 0.105 \\ \text { S9 } & -0.000126 & -4.27 \mathrm{E}-04 & -0.013 & -9.05 \mathrm{E}-03 & -0.012 & -9.99 \mathrm{E}-03 \\ \text { S10 } & -0.040346 & -0.012 & -0.396 & -0.343 & -0.366 & -0.338 \\ \text { S11 } & -0.059759 & -0.019 & -0.599 & -0.534 & -0.588 & -0.563 \\ \text { S12 } & -0.043462 & -0.015 & -0.463 & -0.415 & -0.458 & -0.435 \\ \text { S13 } & -0.000764 & -9.81 \mathrm{E}-04 & -0.026 & -0.027 & -0.036 & -0.033\end{array}$

Measured Scheme (in plane)

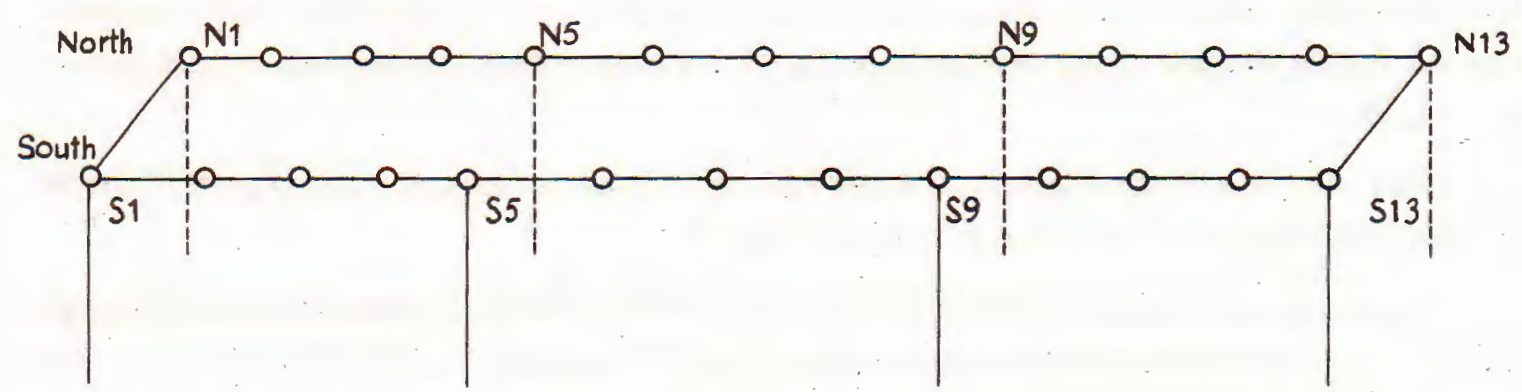

○ Measured Location 
Two cases of detecting appropriated models (undamaged and E-4 case) will be considered in this paper.

\subsection{Finite Element modeling of the $I-40$ bridge}

Based on the I-40 bridge data (Fig. 1), we built the finite element model of the bridge superstructure. This model contains a total of 575 nodes, 604 elements. Four node shell elements were chosen to model the girder flange, the web of two girders, the floor beam, the stringer and the bridge decks. Two node beam elements were used to model the cross-bracing. Detailing of the bridge model at the abutment end is shown on Fig. 2.

For the damage type described above, the change of the finite element model in the damage location is shown in Fig. 3

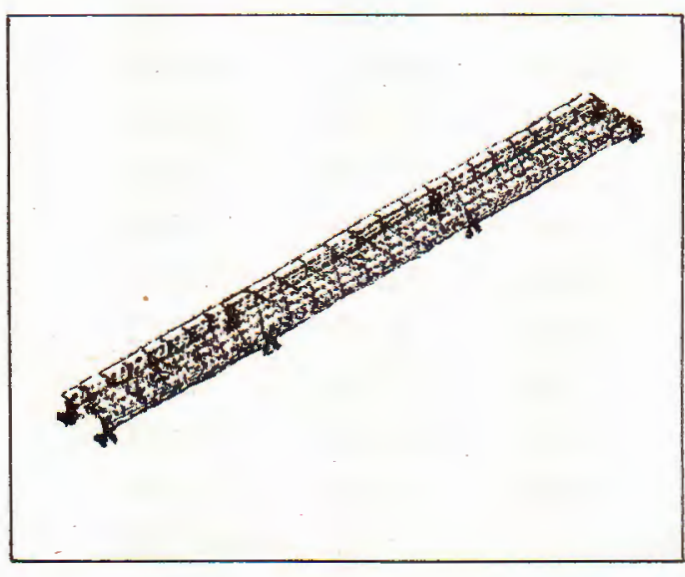

Fig. 2. The finite element model of I-40 bridge

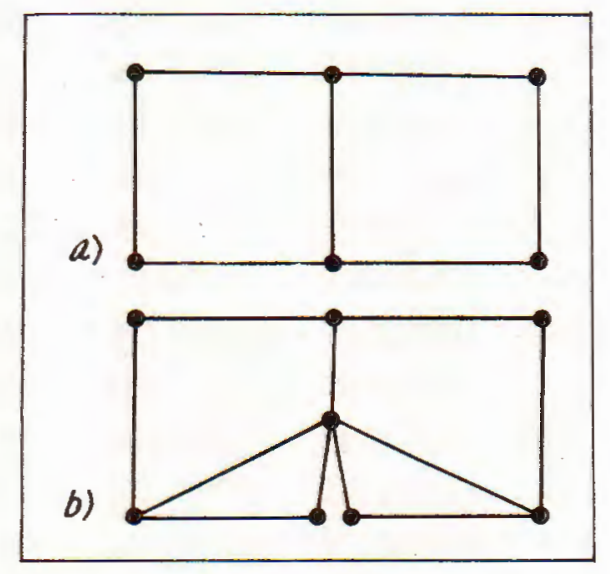

Fig. 3. Finite element modeling before (a) and after (b) damage

\subsection{Detecting appropriate models in the damage library}

For the convenience of comparison, we develop sd a program (in C language) to display the measured mode shape in graphics mode. Fig. 4 displays three experimental mode shapes using this program and corresponding mode shapes calculated by SAP90.

The results of correlation matrices between theoretical and experimental mode shapes according to (3.1) are given in Table 2.

So, the undamaged model in library is compared with 5 experimental damage cases. The correlation matrices are given in $2^{\text {nd }}$ column of Table 2 . We can see that the two first correlation matrices satisfy the condition (3.3), therefore the two first experimental cases are regarded as undamaged. The rest of the cases 
are considered as damaged. Using the $4^{\text {th }}$ damaged model in the library and comparing it with experimental damaged cases, the results are presented in $3^{\text {rd }}$ column of Table 2. Using condition (3.3), it is easy to find that the $5^{\text {th }}$ experimental damaged case is in accordance with the $4^{\text {th }}$ damaged model in library.

Table 2

The correlation matrices between theoretical and measured mode shape

\begin{tabular}{|c|c|c|c|c|c|c|}
\hline Case & Undamag & ed case (ir & n library) & $4^{\text {th }}$ damag & ed cases & (n library) \\
\hline & 0.974 & $8.04 \mathrm{E}-4$ & $7.4 \mathrm{E}-2)$ & 0.95 & $2.38 \mathrm{E}-2$ & $8.77 \mathrm{E}-4$ \\
\hline + Und. & $8.04 \mathrm{E}-4$ & 0.973 & $2.8 \mathrm{E}-4$ & $2.38 \mathrm{E}-2$ & 0.809 & $2.65 \mathrm{E}-2$ \\
\hline & $7.4 E-2$ & $2.8 E-4$ & 0.91 & $9.63 \mathrm{E}-2$ & $2.65 \mathrm{E}-2$ & 0.84 \\
\hline & 0.951 & $4.46 \mathrm{E}-4$ & $7.64 \mathrm{E}-2)$ & 0.96 & $1.13 \mathrm{E}-2$ & $1.51 \mathrm{E}-3)$ \\
\hline$+E-1$ & $4.64 \mathrm{E}-4$ & 0.943 & $1.31 \mathrm{E}-5$ & $1.13 \mathrm{E}-2$ & 0.807 & $2.5 \mathrm{E}-2$ \\
\hline & $(7.64 \mathrm{E}-2$ & $1.31 \mathrm{E}-5$ & 0.907 & $1.51 \mathrm{E}-2$ & $2.5 \mathrm{E}-3$ & 0.855 \\
\hline & 0.976 & $2.19 \mathrm{E}-5$ & $7.55 \mathrm{E}-2)$ & 0.958 & $1.62 \mathrm{E}-2$ & $5.76 \mathrm{E}-4)$ \\
\hline$+\mathrm{E}-2$ & $2.19 \mathrm{E}-5$ & 0.969 & $1.26 \mathrm{E}-4$ & $1.62 \mathrm{E}-2$ & 0.801 & $2.83 \mathrm{E}-2$ \\
\hline & ( 7.55E-2 & $1.26 \mathrm{E}-4$ & 0.899 & $5.76 \mathrm{E}-2$ & $2.83 \mathrm{E}-2$ & 0.85 \\
\hline & 0.969 & $6.99 \mathrm{E}-6$ & $8.36 \mathrm{E}-2)$ & 0.95 & $1.85 \mathrm{E}-2$ & $2.42 \mathrm{E}-3)$ \\
\hline$+E-3$ & $6.99 E-6$ & 0.968 & $1.05 \mathrm{E}-4$ & $1.85 \mathrm{E}-2$ & 0.809 & $2.37 \mathrm{E}-2$ \\
\hline & $8.36 \mathrm{E}-2$ & $1.05 \mathrm{E}-6$ & 0.882 & $2.42 \mathrm{E}-2$ & $2.73 \mathrm{E}-3$ & 0.846 \\
\hline & 0.801 & 0.129 & $9.63 \mathrm{E}-2)$ & 0.945 & $5.09 \mathrm{E}-2$ & $2.31 \mathrm{E}-2)$ \\
\hline$+E-4$ & 0.129 & 0.891 & $5 E-3$ & $5.09 \mathrm{E}-2$ & 0.91 & $2.48 \mathrm{E}-3$ \\
\hline & $9.64 \mathrm{E}-2$ & $5 \mathrm{E}-3$ & 0.902 & $2.31 \mathrm{E}-2$ & $2.48 \mathrm{E}-3$ & 0.907 \\
\hline
\end{tabular}

\section{Conclusion}

Formula (3.1) and condition (3.3) can be used to detect the appropriate model of the structure in the damage library based on the correlative comparison of theoretical and measured mode shapes. Also, this technique can be used to detect the damage location in the structure. When the actual damage does not correspond with one of the modeled scenarios, model updating should be based on other inspection methods (for example, visual and non-destructive methods), and that model can be added to the damage library. If there are some models in the damage library satisfying condition (3.3), it is required to use other methods for support. 

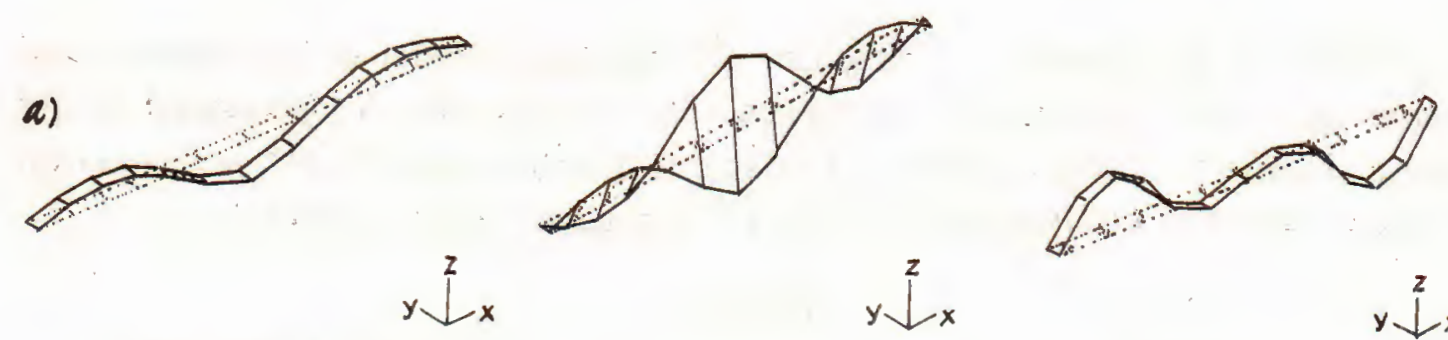

$\mathcal{L}^{z} x$
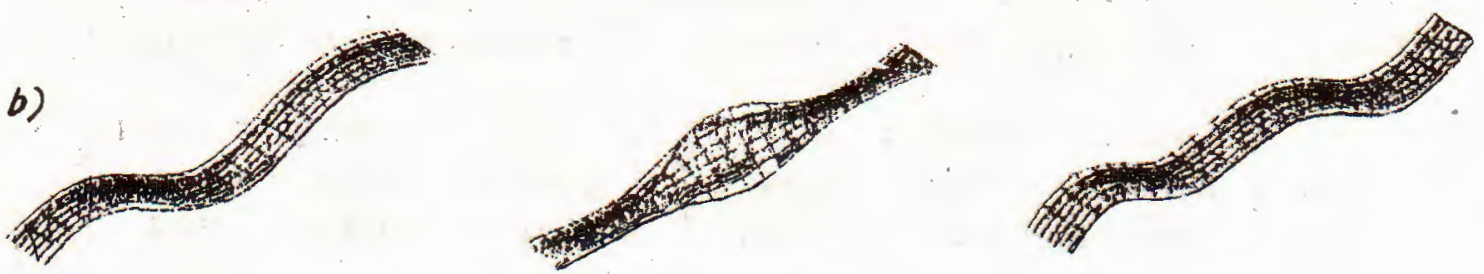

Fig. 4. The experimental and theoretical mode shapes

\section{REFERENCES}

1. Nguyễn Cao Mệnh, Nguyễn Tiến Khiêm, Đỗ Sơn. Quy trình chần đoán dàn khoan biển cố định bằng các đặc trưng động lực học. Tuyển tập công trình Hội nghị CHVRBD lần thứ 5 - Hà Nội 1996.

2. Ewins D. J. Modal testing: Theory and practice, Research Study Press LTD, Taunton, Somerset, England 1984.

3. Friswell M. I., Penny J. E. The use of vibration data and model updating to detect damage, Elsvier Applied Science, London, England 225-235 (1992).

4. Farrar C. Jauregui D. Damage detection algorithms applied to experimental and numerical modal data from the I-40 bidge, Los Alamos, New Mexico, January 1996.

5. Cawley P., Adams R. D. The location of defect in structure from measurements of natural frequencies, Journal of strain analysis Vol. 14, No 2, 1979.

Received May \$1, 2000

\section{SƯ DỤNG CÁC ĐẶC TRUNG DAO ĐỘNG ĐỂ CẬP NHẬT MÔ HÌNH KẾT CẨU}

Việc nghiên cứu cập nhật mô hình tính toán của kết cấu dựa trên các đặc trưng dao động của nó đã được nhiều tác giả nghiên cứu. Một trong các phương pháp được sử dụng là sử dụng các đặc trưng dao động để tìm kiếm mô hình kết cấu phù hợp trong thư viện các hư hơng đã được tính toán trước. Bài này đề xuất thuật toán tìm kiếm mô hình hư hóng trong thư viện hư hỏng dựa trên cơ sở phát triển phương pháp tiêu chuẩn bền vững dao động (Modal Assurance Criteria) do Ewins D. J. đưa ra. Các kết quả đo đạc thực nghiệm trong [4] được sử dụng đễ tính toán minh họa. 